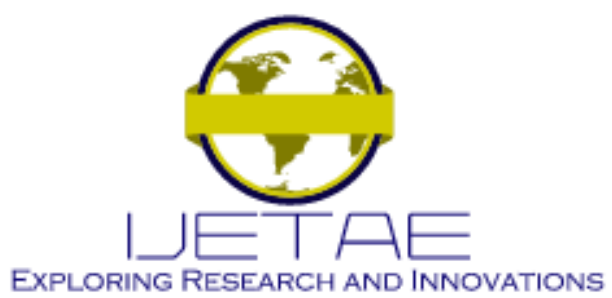

International Journal of Emerging Technology and Advanced Engineering

Website: www.ijetae.com (E-ISSN 2250-2459, Scopus Indexed, ISO 9001:2008 Certified Journal, Volume 11, Issue 08, August 2021)

Manuscript Received: 10 July 2021, Received in Revised form: 09 August 2021, Accepted: 14 August 2021

DOI: 10.46338/ijetae0821_03

\title{
Fast IQ Amplitude Approximation Method for ASIC Digital System
}

\author{
Giao N. Pham ${ }^{1}$, Anh N. Bui ${ }^{2}$, Binh A. Nguyen ${ }^{3}$, Tung V. Nguyen ${ }^{4}$, Hai T. Nguyen ${ }^{5}$ \\ ${ }^{1,2}$ Dept. of Computing Fundamentals, FPT University, Hanoi, Vietnam \\ ${ }^{3,4}$ CT Department, FPT University, Hanoi, Vietnam

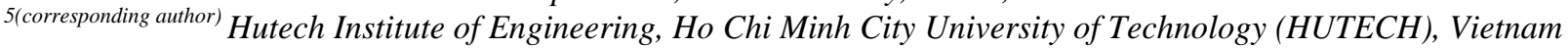

\begin{abstract}
In some modules of digital systems, such as Fast Fourier Transform (FFT), Discrete Fourier transform (DFT), IQ (in-phase and quadrature components) modulation/ demodulation, the outputs use the complex data formed $\boldsymbol{x}+\boldsymbol{j} \times \boldsymbol{y}$, and the calculation of its magnitude value $r=\sqrt{x^{2}+y^{2}}$ are required. In software digital signal processing platform, the multiplication and square root operations are executed by using its math library; however, in Application specific integrated circuit (ASIC) digital system design, the implementation of those operators via Coordinate Rotation Digital Computer (CORDIC) algorithm requires the numerous resources and delays. So, in this paper, we present a fast approximation method for above problem which takes a small delay but acceptable accuracy for AISC digital system design.
\end{abstract}

Keywords-ASIC, Digital system design, FFT, DFT, Fast amplitude approximation, Max-Min approximation.

\section{INTRODUCTION}

Signal processing has been used to transform or manipulate analogue or digital signals for a long time. Nowadays, many intelligent electronic consumer devices can be seen anywhere around us. Inside them, the digital signal processing (DSP) modules can be said to be the most important ones or fundamental to digital technology, which includes many advantage technologies and have various type such as speed processing, audio processing, image processing, information system, control system, seismology, telecommunication system, $[1,2]$.

Application specific integrated circuit (ASIC) signal processor are necessary to achieve the high performance, low power requirements of modern applications. The two importance issues of ASIC are the number representation and the implementation of algebraic operations. But as the requirement of modern application, the complex mathematical operations can be faced a lot.
There are many researchers involve adapting those problem such as fast calculation time, efficient using of resources; for examples fixed point number presentation, floating point number, multiply accumulator (MAC), sum of product (SOP), computation of some special function by CORDIC [3, 4]. Among them, the linear approximations for computing method have an important and efficient. There is the trade-off when using it and depends on the type of applications, we can choose the best way and best suitable method.

In this paper, we are going to discuss about an application of linear approximations for the calculation of magnitude of complex number. In telecommunication signal processing methods, the complex numbers are used to represent the signal in modulations and Fourier transform modules. The proposed method is called IQ amplitude estimation which is discussed in section 2. And the HW implementation via Verilog HDL is discussed in section 3 .

\section{IQ AMPLITUDE ESTIMATION PROBLEM AND PROPOSED METHOD}

In some application such as FFT, DFT, image processing, IQ demodulator, automatic gain control (AGC) of an incoherent receiver that uses complex data in following form:

$$
\text { output }=x+j y
$$

where $\mathrm{x}$ is denoted the real part of output and $\mathrm{y}$ is denoted the image part of output. Then, the magnitude of output is given as $r=\sqrt{x^{2}+y^{2}}$. The purpose of fast estimation method is to approximate $r$ as:

$$
r=\alpha \times \max \{|x|,|y|\}+\beta \times \min \{|x|,|y|\}
$$

Table I gives many possible values for $\alpha, \beta$ and the Figure 1 gives the effective comparison between them. 


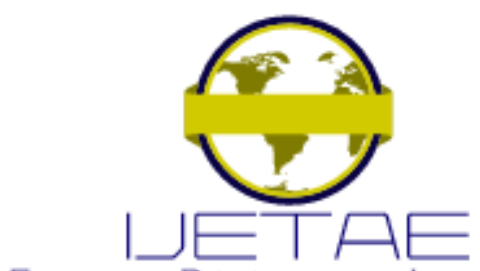

EXPLORING RESEARCH AND INNOVATIONS

International Journal of Emerging Technology and Advanced Engineering

Website: www.ijetae.com (E-ISSN 2250-2459, Scopus Indexed, ISO 9001:2008 Certified Journal, Volume 11, Issue 08, August 2021)

Table I.

COEFFICIENT CHARACTERISTICS OF PROPOSED APPROXIMATION FOR CASE OF $L_{0}(\alpha=1, \beta=1), L_{1}\left(\alpha=1, \beta=\frac{1}{4}\right), L_{\infty}\left(\alpha=1, \beta=\frac{3}{8}\right)$.

\begin{tabular}{|rrrrcc|}
\hline$\alpha$ & $\beta$ & $L_{1}$ & $L_{\infty}$ & eff. bits & Comments \\
\hline 1 & 1 & $27.1 \%$ & $41.4 \%$ & 1.2 & $L_{0}$ \\
0.943 & 0.386 & $1.97 \%$ & $6.0 \%$ & 4.1 & $L_{1}$ optimum \\
1 & $1 / 4$ & $3.17 \%$ & $11.6 \%$ & 3.1 & $L_{1}$ approximation \\
0.962 & 0.396 & $2.45 \%$ & $4.0 \%$ & 4.6 & $L_{\infty}$ optimum \\
1 & $3 / 8$ & $4.22 \%$ & $6.8 \%$ & 3.9 & $L_{\infty}$ approximation \\
\hline
\end{tabular}

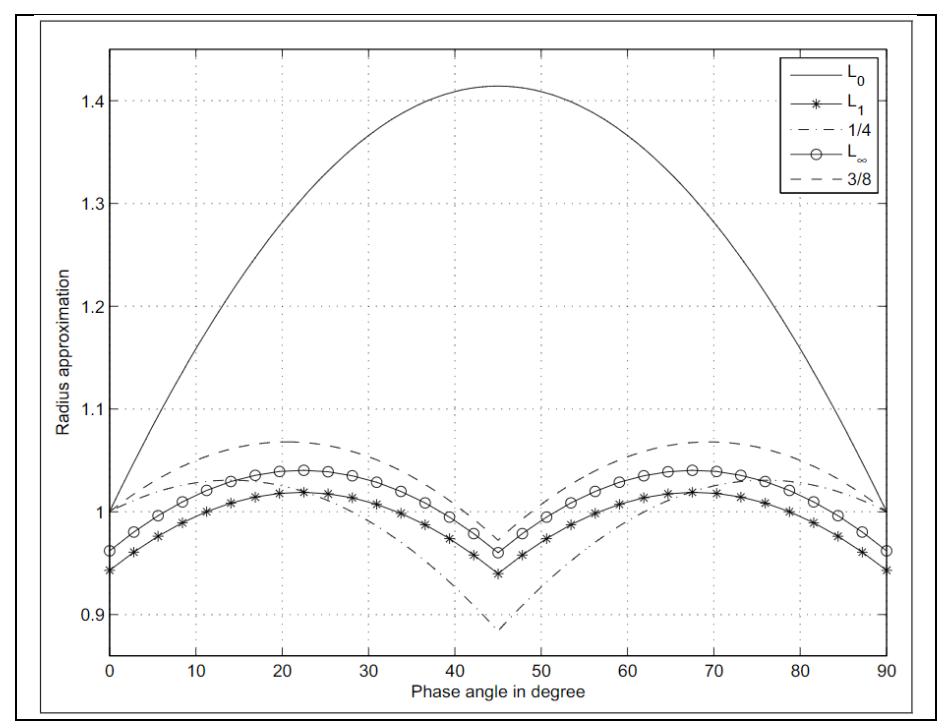

Figure I. Magnitude approximation of proposed approximation for case of $L_{0}(\alpha=1, \beta=1), L_{1}\left(\alpha=1, \beta=\frac{1}{4}\right), L_{\infty}\left(\alpha=1, \beta=\frac{3}{8}\right)$.

\section{HW-VERILOG HDL IMPLEMENTATION AND RESULTS}

\section{A. $H W$ Verilog HDL implementation}

The HW implementation is done via Verilog HDL language as Figure 2, which is used in FFT-256 module for output approximation as figure 3 . The proposed method just takes 3 clock cycle and with small error.

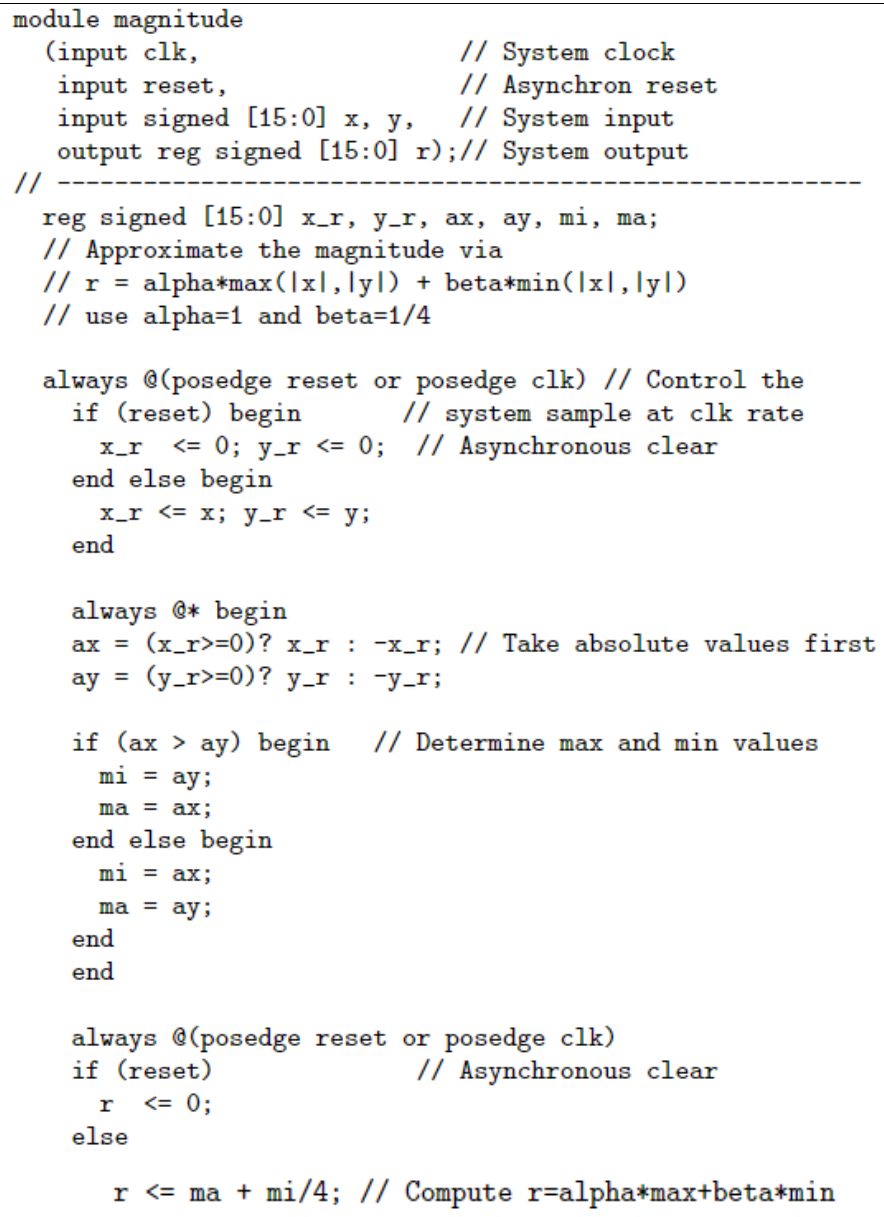

Figure II. Verilog code for proposed approximation method in case of

$$
\alpha=1, \beta=\frac{3}{8} \text {. }
$$




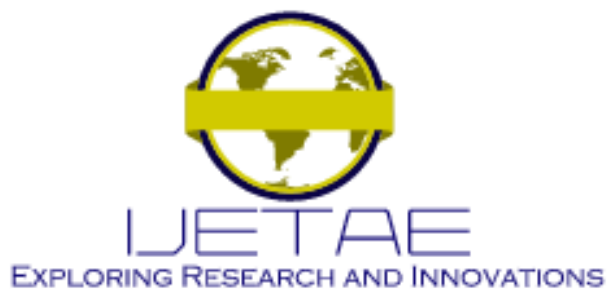

International Journal of Emerging Technology and Advanced Engineering

Website: www.ijetae.com (E-ISSN 2250-2459, Scopus Indexed, ISO 9001:2008 Certified Journal, Volume 11, Issue 08, August 2021)

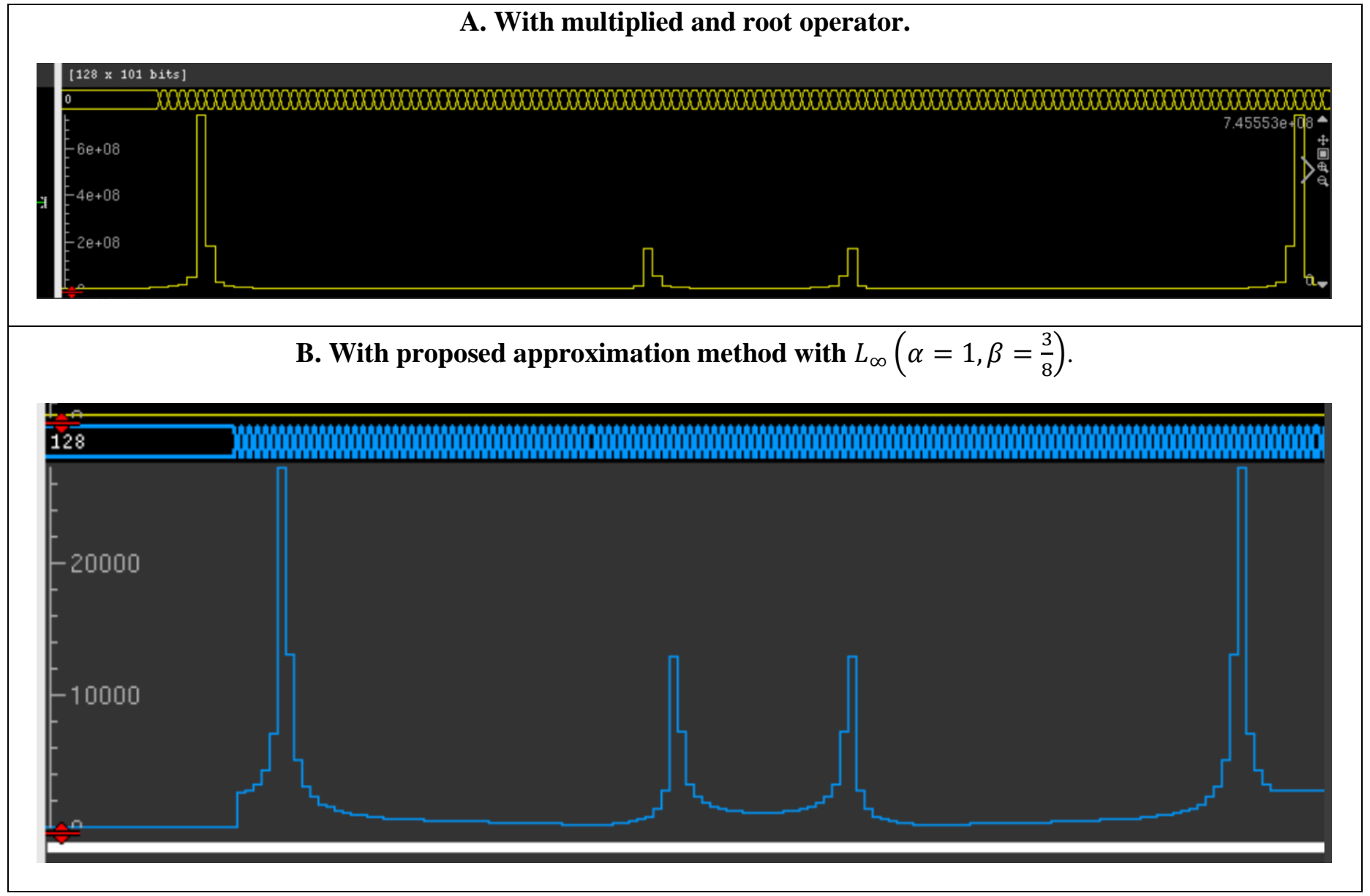

Figure III. Simulation result for FFT-128 modules where the output amplitude is calculated via two methods

B. An improvement of proposed approximation method with more accuracy

To get more accuracy, we can extend the proposed algorithm as below:

$$
r=\left\{\begin{array}{cc}
x+\frac{1}{8} y & \text { for } x \geq 3 y \\
\frac{7}{8} x+\frac{1}{2} y & \text { for } x \leq 3 y
\end{array}\right.
$$

This algorithm is better accuracy in comparison with the $L_{1}\left(\alpha=1, \beta=\frac{1}{4}\right), L_{\infty}\left(\alpha=1, \beta=\frac{3}{8}\right)$ which are discussed in section 3.A.

\section{CONSLUSION}

In this paper, a novel hardware design for fast magnitude estimation for a complex number is discussed in detail. The proposed method is useful for hardware design of many digital systems such as FFT, DFT, IQ modulation/ demodulation. This document will be great references for engineers who working at ASIC digital design field.

\section{Acknowledgement}

This work is supported by FPT University, Hanoi, Vietnam; and Hutech Institute of Engineering, Ho Chi Minh City University of Technology (HUTECH), Vietnam. 


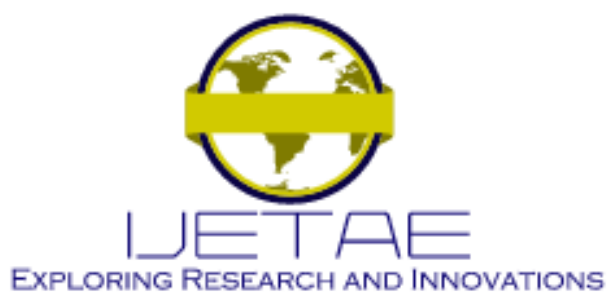

International Journal of Emerging Technology and Advanced Engineering

Website: www.ijetae.com (E-ISSN 2250-2459, Scopus Indexed, ISO 9001:2008 Certified Journal, Volume 11, Issue 08, August 2021)

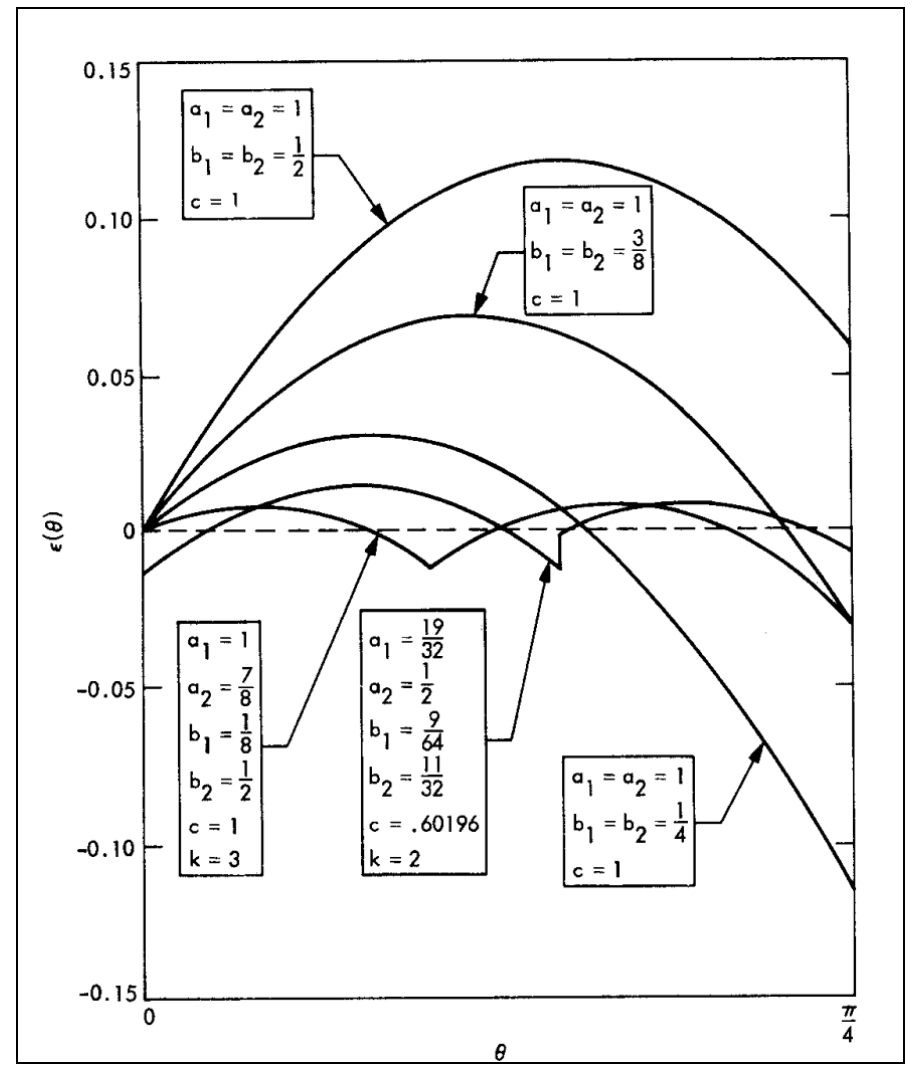

\section{REFERENCES}

[1] Nguyen, D. M. et. al. New Constructions of Quantum Stabilizer Codes Based on Difference Sets. Symmetry 10(11), 655. 2018.

[2] Hai T. Nguyen et. Al. Novel Quantum Communication Protocol and its Simulation in IBM Quantum Simulator. Int. J. of Emerging Technology and Advanced Engineering, Vol. 11, No. 7, pp. 8-12, Jul. 2021.

[3] Phuong. H. Lai et. al. Signal generator module based on CORDIC algorithm: Design, implementation, and verification using MATLAB and Verilog HDL. Int. J. of Advanced Trends in Computer Science and Engineering. 9(5), 8703-8708, 2020.

[4] B.K. Levitt. et. al. An Improved Digital Algorithm for Fast Amplitude Approximations of Quadrature. DSN Progress Report, 42-40, 1977.

Figure IV. Comparison of amplitude approximation errors between improvement method and two proposed methods. 